\title{
KNOWLEDGE MANAGEMENT, ORGANIZATIONAL AMBIDEXTERITY, AND MANUFACTURING PERFORMANCE IN THE ERA OF INDUSTRY 4.0: A PROPOSED MODEL
}

\author{
Seng Cheong Cheah ${ }^{1,2}$ and Cheng Ling Tan ${ }^{1}$ \\ ${ }^{1}$ Graduate School of Business, Universiti Sains Malaysia, 11800 USM, Penang, Malaysia \\ 2PKT Logistics Group Sdn. Bhd., 40460 Shah Alam, Malaysia
}

\begin{abstract}
Fourth Industrial Revolution (IR4.0) is changing the landscape of global manufacturing. As a developing nation, Malaysia's manufacturing sector is a leading contributor to the nation's GDP but its growth is in declining mode recently. Facing competition from countries with lower labour cost, Malaysia needs alternative ways to achieve competitive advantage. Many of its manufacturers are new to IR4.0 and also cautious of investing in such technologies to increase its manufacturing performance. Realizing this, Malaysia's government introduced a policy on IR4.0 by focusing on the people, process and technology. The goal is to increase the skill set of the existing workforce through knowledge enhancement and adoption of advance manufacturing technologies. However, high level of transformation is needed, collaboration with external parties is important, and internal business processes and operating models need to change too. Many of them are lack in slack resources to pursue both explorative and exploitative learning. Organizational ambidexterity, which is the ability of a firm to manage both of these activities is crucial for proper knowledge management and improving manufacturing performance. The objective of this paper is to examine such interconnection from the context of a developing country as information from extant literature is scarce, especially on the balanced approach to source, transfer and protect the knowledge for optimum gain in manufacturing performance. Three main activities of knowledge management will be examined namely external knowledge sourcing, knowledge mobility and knowledge protection. The inclusive of knowledge protection also narrow the literature gap as it tends to be left out in previous studies due to its conflicting nature with other knowledge management activities. All the hypotheses and resulted conceptual model will be grounded with theories of Resource-Based view (RBV), Knowledge-Based View (KBV), Dynamic Capabilities and OA.
\end{abstract}

ARTICLE HISTORY

Received:2-12-2019

Accepted:24-2-2020

\section{KEYWORDS}

Knowledge management,

Organizational

ambidexterity,

Manufacturing

performance,

Malaysia's manufacturing

firms

Industry 4.0

\section{INTRODUCTION}

This paper examines the relationship between Knowledge Management (KM), Organisational Ambidexterity (OA), and Manufacturing Performance (MP) and how KM and OA affect MP in Malaysia's manufacturing industry. Present literature mostly shows the direct relationship between a generalized concept of KM and OA and there is a lack in detail of how and which KM activities have an impact on OA, and what kind of OA related activities will affect MP. The studies of KM and MP are also limited (Tan \& Wong, 2015) and even rarer to locate studies with these three constructs, especially in a developing country setting. To fill these gaps, this research was conducted to empirically examine the interconnection of these constructs by breaking down individual related activities of KM and their relationship to OA. Furthermore, this paper also covers the mediating factor of OA on KM and MP. Activities related to KM are diverse, but scholars appear to have a consensus that knowledge acquisition, knowledge sharing, and knowledge application are the main activities (Al-Sa'di et al., 2017; Liu, 2012; Patel et al., 2012; Zhou \& Li, 2012). However, this study takes on a more specific approach by examining three important activities of KM namely External Knowledge Sourcing (EKS), Knowledge Mobility (KMobility), and Knowledge Protection (KP). All these three dimensions of KM are posited to have a positive relationship with OA. Furthermore, OA indicates a positive mediating effect on KM and MP. All the hypotheses are grounded with theories of RBV, KBV, DC, and OA. However, at the core of these theories, having the right knowledge is important. Given such position, KBV being the main theory states that knowledge application is key (Grant, 1996), and the ability for the firm to properly manage the knowledge resources is vital for firm's decision making. KBV binds all these theories and provides a comprehensive understanding of the theoretical framework. Both OA and KM are widely researched areas within their respective field and have gained a certain level of knowledge maturity, in which combining them into this study will provide a strategic orientation towards addressing the existing problems. As such, it is the interest of this study to empirically analyze these problems and to find an answer to the following problem statement:

How KM and OA affect MP in Malaysia's manufacturing industry at this point? 


\section{LITERATURE REVIEW}

\section{Manufacturing performance}

In a volatile global market, measuring the performance of the firm is a necessity to ensure the production efficiency and effectiveness are aligned to the organization's business strategies (Antunes et al., 2017). Moreover, existing literature does not indicate firm measurements or indicators for MP. Depending on the context of the study, its terminology changes accordingly too, and usually being recognized as Firm Performance, Organizational Performance, Operational Performance, and Manufacturing Strength. Furthermore, literature is showing that it can be measured subjectively or objectively, and according to Ruiz-Jiménez \& Fuentes-Fuentes (2013), quantifiable financial figures are popular indicators for the objective measure even though it may not reflect the actual MP which is more complex and indirect. As for subjective measure, some scholars stressed that these indicators are not fixed and subjected to the nature of the market that the manufacturers operate in, and only multifaceted measurements are able to capture the real MP (Vázquez-Bustelo et al., 2007). Meanwhile, others claimed that operational performance is a reflection of how well a manufacturer handles its KM to facilitate improvement in products and processes (Al-Sa'di et al., 2017). The common measurement indicators are cost and quality (Patel et al., 2012) but in a more recent study, some scholars also included flexibility and delivery as the common indicators (Al-Sa'di et al., 2017; Tamayo-Torres et al., 2017). However, through technology sourcing, a firm needs to know how the new technology can improve the firm's performance. Hence, certain scholars also included innovative performance such as the number of innovative products produced (Abdallah et al., 2016) or patent counts (Hagedoorn \& Cloodt, 2003; Rothaermel \& Alexandre, 2009) as some of the indicators to measure a firm's performance.

At the same time, a firm needs to have ambidexterity in terms of learning for technology sourcing because it will prevent premature failure (Rothaermel \& Alexandre, 2009) and improve the firm performance by balancing both the explorative and exploitative innovation output (Kim et al., 2019). Furthermore, extant literature also indicates a strong positive relationship between KM and MP (Aboelmaged, 2014; Tan \& Wong, 2015). Dezi et al. (2019) asserted that merely access to knowledge would not ensure OA within the firm, and consequently, a proper KM is still required. From all these perspectives, it appears that there is a connection between KM, OA, and MP. This paper will propose a model on how the firm can source, share, utilize and protect its knowledge asset and its impact on the firm's ability to balance up both explorative and exploitative learning to support its MP. As such, both KM and OA will be the predictors for MP, and the mediating effect of OA will be examined too. Furthermore, some scholars are also cautious that it is risky to analyze firm performance based on the one-dimensional indicator as it may not reflect the true impact of the predictor (Raisch \& Birkinshaw, 2008). Building on this argument, this study will be using multi-dimensional subjective measures indicators which are cost, flexibility, quality, and delivery to measure the dependent variable MP, with KM and OA as the independent variables.

\section{Organizational ambidexterity}

In a highly globalized economy, market dynamic with evolving customer demands is one of the challenges that many firms are facing. With limited resources on hand, especially knowledge resources, many will be at risk of being left behind (MITI, 2018). OA is defined “as an organization's ability to be aligned and efficient in its management of today's business demands while simultaneously being adaptive to changes in the environment" (Raisch \& Birkinshaw, 2008, p. 375). Strategic management literature refers to such ability as pursuing both the exploration and exploitation activities, and according to March (1991), both these activities are mutually exclusive, and the firm needs to strive for the right balance between them to gain business sustainability and growth. After the seminal work of March (1991) on OA concerning technological innovation, many scholars started to examine this concept from various research areas, and it is usually related to organizational learning (Patel et al., 2012), strategic management (Dezi et al., 2019), technological innovation (March, 1991) and business orientation (Sahi et al., 2019). Some scholars claimed that it is always a challenge for a firm to implement flexibility (exploration) and quality (exploitation) production strategy simultaneously as both require different capabilities and usually firm ended up choosing either one of them (Qamar et al., 2019). However, this leads to another setback as a firm that focuses on exploration might end up with many underdeveloped ideas and conversely, a firm that focuses on exploitation may miss out on new market opportunities or have products that are not meeting customers' preferences (March, 1991). As such, a firm needs to have the right approach according to the dynamic of the market environment.

In this study, the focus will be on the aspect of explorative and exploitative learning activities and how the firm can optimize a balanced approach of EKS, KMobility, and KP to increase its MP. Literature indicated that it is always a paradox when determining what constitutes the right balance. Raisch and Birkinshaw (2008) stated that whether a firm should be ambidextrous in both activities or settle with a trade-off between them remain inconclusive. In addition, Leonard-barton (1992) remarked that if the firm focuses on one particular learning activity, then it will result in core rigidities, which are a set of inappropriate knowledge that will hinder the development of its core capabilities. As a result, scholars started to measure and validate the impact of OA on firm performance empirically (Raisch \& Birkinshaw, 2008). Seminal work by He and Wong (2004), managed to empirically confirm that a balance between exploration and exploitation related strategies in a firm will have a positive impact on the sales growth. However, other scholars discovered that the interactions of both exploration and interaction activities are generating a negative effect on the firm's innovation performance. Empirical results also indicated inconclusive findings, and this has prompted Raisch and Birkinshaw (2008) to urge future studies to consider multi-dimensional performance indicators instead of a single- 
dimensional indicator (He \& Wong, 2004) for analyzing the OA performance linkage to avoid potential bias result. Building upon such a premise, this paper will analyze the interaction between OA and KM and their impact on MP.

\section{Knowledge management}

There is a common understanding that we are living in the era of a "knowledge-based economy" (Liebeskind, 1996; OECD, 2005) where competitive advantage is dictated by knowledge instead of cheap labor or raw material (Liebeskind, 1996). This notion has resulted in a booming of studies on KM. Many scholars believe that KM consists of three key activities namely knowledge creation or acquisition, knowledge transfer or sharing, and knowledge utilization or application (Al-Sa'di et al., 2017; Liu, 2012; Patel et al., 2012; Zhou \& Li, 2012). The firm needs to compensate for knowledge that they lack through external sourcing, and there is a consensus among scholars that EKS is vital for a firm to increase its knowledge base and performance benefit (Brunswicker \& Vanhaverbeke, 2015; Lin et al., 2013; Liu, 2012; Zhou \& $\mathrm{Li}, 2012$ ). In order to fully gain from this new knowledge, firms will need to spread it effectively among their employees. Knowledge sharing entails spreading and transferring of tacit and explicit knowledge across the whole organization (Tan \& Wong, 2015). Knowledge utilization involves the conversion of this knowledge into actions that brings benefits to the organization. Meanwhile, KMobility consists of two steps process which requires knowledge sourcing and followed by knowledge utilization with the support of knowledge sharing (Liu, 2012). KMobility is being adopted as it provides a greater understanding of both perspectives. While exploring new learning, it is equally important not to abandon internal core knowledge, and KP stresses the need to prevent expropriation of the firm's intellectual property and limit imitation of its products by reducing the exposure of critical knowledge (Liebeskind, 1996). However, implementing KP requires the firm to balance between the key knowledge and the cost to protect it. Moreover, too much of KP will hinder Kmobility, and too little of it will lead to knowledge leakage. As a result, there is a lack in the study for $\mathrm{KP}$ and some scholars even dictated that it should not be studied together with other KM activities due to potential conflict (Liao \& Wu, 2010; Liu, 2012). Nevertheless, it is irrational to ignore KP, especially for firms striving to be competitive in a "knowledge-based economy." In summary, this study will focus on EKS, KMobility, and KP as the main factors for KM.

\section{Development of hypotheses}

\section{Knowledge management and organizational ambidexterity}

Knowledge obtained from external network actors, such as customers, suppliers, and competitors, will enable a firm to facilitate the integration of both internal and external knowledge through KMobility. Thus, this will bring forward greater accessibility for both exploration and exploitation related activities for the firm (Dezi et al., 2019). In addition, another separate study indicates that both EKS and internal knowledge sourcing are indeed complementing each other, and the result implies knowledge from an external source will be an important source for the firm to learn exploitatively and achieve the best innovation outcome (Doran \& Mccarthy, 2019). In order to have multiple sources of new knowledge, collaboration with external parties is important (Olander et al., 2014; Patel et al., 2012) and close ties will further facilitate the sharing of confidential information that will benefit the ambidextrous orientation of the firm (Dezi et al., 2019; Xie et al., 2019). Previous studies also confirmed that if a firm continues to pursue external sourcing of new knowledge, then it will be able to identify an opportunity to enter a new market or create a new market, concomitantly generates the quintessential information for the firm to balance up its exploration and exploitation related activities (Sahi et al., 2019; Tang et al., 2019). From the same perspective, an ambidextrous firm can gain a competitive advantage in conjunction with EKS due to its mature development roadmap that continues to search for new ideas that can be incorporated into existing innovation strategy (Vrontis et al., 2017). As for entrepreneurially oriented firms, EKS is key for their OA learning through always sensing for new changes in the external environment, and adopting such knowledge and exploiting it with existing knowledge for new-product development that meets market demands (Sahi et al., 2019).

It is obvious that a firm needs to expand its knowledge base through external collaboration, but with proper KMobility, a firm will be able to identify the right knowledge to source and expand its application through sharing. According to Han (2019), if a firm practices explorative knowledge sharing, it will allow the firm to assess the value of its knowledge through market response and simultaneously recognize changes in technology trends to avoid knowledge lock-in. On the other hand, if a firm is exploiting its knowledge, it will uncover the weaknesses and bottleneck processes within the firm. Therefore, both forms of KMobility will reinforce the firm to continually adjust its resources to achieve a balance learning capability at all times. As for the firm with limited resources to practice OA, they can form a network with various external partners to exchange knowledge of common interest through KMobility practice, and in return together streamline the process of the supply chain. Such practice will eventually free up resources for the firm to implement OA that benefits the supply chain (Partanen et al., 2020). This kind of networking can be regarded as collaboration ties that facilitate EKS, which then revitalize the internal knowledge base that complements exploitative learning (Xie et al., 2019). As a result, the firms' ambidextrous activities will improve. According to an empirical study by Dezi et al. (2019) on 119 Italian SMEs, EKS alone will not make the firm successful, and KM is required to achieve better performance. They claimed that KMobility is one of the key activities that facilitate the acquisition, sharing, and implementation of new knowledge, which consequently improve upon the firm's OA and competitive advantage. 
As per earlier discussion, collaboration with external parties is unavoidable for a firm to gain new knowledge and also to share knowledge in return for a sustainable mutual benefit (Olander et al., 2014). While the firm is pursuing such explorative learning, there is a potential for the firm to over-expose its core knowledge for the competitive gain of others (Estrada et al., 2016). KP is crucial to limit such exposure, but too much of it will hinder knowledge exchange, and this leads to a KM paradox (Liebeskind, 1996; Olander et al., 2014). At the same time, KP will incur the cost, and it will be over costly to protect all the knowledge (Liebeskind, 1996). To overcome all these paradoxes, Oorschot et al. (2018) proposed a conceptual knowledge sharing strategy known as the continuous reciprocity loop. They claimed that both provider and recipient of the knowledge will seek continuous mutual benefit by limiting the knowledge to be shared with the intent to let the other party into believing that there is more to gain from the relationship. In this sense, KP can indeed enhance the organization's ambidexterity level by generating awareness in managing its exploration and exploitation learning activities. According to Liebeskind (1996), not all firms are equally capable of managing the inflow and outflow of knowledge. Still, as firms devise strategies to manage this trade-off over time, they will be able to implement an organizational arrangement that promotes certain knowledge while protecting their core knowledge. Such an arrangement is indeed OA, and KP will influence the implementation of OA in the firm. Table 1 highlights the recent empirical findings of KM and OA, as has been discussed earlier. Based on the aforementioned arguments, the following hypotheses are posited.

H1. EKS is positively related to OA.

$H 2$. KMobility is positively related to OA.

$H 3 . \mathrm{KP}$ is positively related to $\mathrm{OA}$.

Table 1. Empirical findings of KM and OA

\begin{tabular}{|c|c|c|}
\hline Authors & KM Activities & Main Findings \\
\hline Xie et al. (2019) & $\begin{array}{l}\text { EKS, } \\
\text { KMobility }\end{array}$ & $\begin{array}{l}\text { External and Internal Knowledge Acquisition mediate the relationship } \\
\text { between Collaborative Ties and Ambidextrous Innovation. }\end{array}$ \\
\hline Dezi et al. (2019) & $\begin{array}{l}\text { EKS, } \\
\text { KMobility }\end{array}$ & $\begin{array}{l}\text { 1. External Embeddedness indirectly enhance ambidexterity through } \\
\text { KM. 2. Ambidexterity positively associates with Firm Performance. }\end{array}$ \\
\hline Sahi et al. (2019) & EKS & $\begin{array}{l}\text { Entrepreneurial orientation has a significant and positive effect on } \\
\text { Operational Ambidexterity. }\end{array}$ \\
\hline Tang et al. (2019) & EKS & $\begin{array}{l}\text { External Search Depth positively affect Innovation Capability, } \\
\text { Exploratory Innovation and Exploitative Innovation. }\end{array}$ \\
\hline $\begin{array}{l}\text { Partanen et al. } \\
\quad(2020)\end{array}$ & KMobility & $\begin{array}{l}\text { Strategic Information Flow mitigates the negative relationship } \\
\text { between Supply Chain Ambidexterity and SME's Performance. }\end{array}$ \\
\hline Han (2019) & KMobility & $\begin{array}{c}\text { Ambidextrous Knowledge Sharing is positively related to Innovation } \\
\text { Performance. }\end{array}$ \\
\hline Yan et al. (2014) & KP & $\begin{array}{l}\text { Ambidexterity (Knowledge Exchange and Knowledge Protection) is } \\
\text { positively related to the performance of cooperation (Common Benefit } \\
\text { and Private Benefit). }\end{array}$ \\
\hline $\begin{array}{l}\text { Estrada et al. } \\
\quad(2016)\end{array}$ & $\mathrm{KP}$ & $\begin{array}{l}\text { When both Internal Knowledge Sharing and Formal Knowledge } \\
\text { Protection Mechanism are present than Competitor Collaboration will } \\
\text { positively impact the firm's Product Innovation Performance. }\end{array}$ \\
\hline
\end{tabular}

\section{Organizational ambidexterity and manufacturing performance}

In a highly volatile market environment, having the ability to continue exploring for fresh ideas or technologies, and exploit them for new product development and manufacturing processes enhancement, will enable a firm to improve its MP and achieve competitive advantage at the same time (Patel et al., 2012). In terms of technology sourcing, an ambidextrous firm will not only able to balance up both explorative and exploitative learning but also manage to narrow the gap between internal technology and new external technology. Such a balancing act will result in tension that warrants the firm to balance the trade-off and prevents the over-reliance on specific technologies that are bound for obsolescence and impacts the firm's performance (Rothaermel \& Alexandre, 2009). This also suggests that OA can facilitate an agile manufacturing strategy by continuously promoting changes to the manufacturing process in responding to the changes in market demand, technology changes, and environmental dynamism (Patel et al., 2012). Within the same perspective, 
Tamayo-Torres et al. (2017) through their empirical analysis of a sand-cone model which represents a sequential process (namely quality, speed, flexibility, and cost) of an improved MP with OA as the enabler, claimed that a firm with the ability to practice ambidexterity through each phase of the sand cone model will eventually drive the MP, especially in high environmental dynamism. Conversely, a recent study on the practice of OA among the SMEs revealed that due to the limited resources among SMEs, pursuing both exploration and exploitation activities may result in negative firm performance. However, the study also indicated that if the SMEs have strong network capabilities and coupled with strategic information flow, take KMobility, for instance, can capitalize on getting the right knowledge and skillset from various external partners to eventually improve on its firm's performance (Partanen et al., 2020). This argument is aligned with the context of this study on the mediating effect of OA on KM and MP, which will be discussed in the subsequent section. In summary, there is a general agreement among the scholars that OA is positively related to MP, as showcased in Table 2 below. Hence, the following hypothesis is developed.

H4. OA will positively affect MP.

Table 2. Empirical finding of $\mathrm{OA}$ and MP

\begin{tabular}{|c|c|c|}
\hline Authors & Data Origin & Main Findings \\
\hline $\begin{array}{l}\text { Tamayo-Torres et al. } \\
\text { (2017) }\end{array}$ & $\begin{array}{l}233 \text { Spanish } \\
\text { Mfg. Firms }\end{array}$ & $\begin{array}{l}\text { Both Exploration and Exploitation act as an enabler to all } \\
\text { the Manufacturing Performance's dimensions. }\end{array}$ \\
\hline $\begin{array}{l}\text { Patel, Terjesen, \& Li } \\
\text { (2012) }\end{array}$ & $\begin{array}{l}852 \text { US } \\
\text { Mfg. Firms }\end{array}$ & $\begin{array}{l}\text { 1.Manufacturing Flexibility mediates Environmental } \\
\text { Uncertainty and Firm Performance. } \\
\text { 2. Operational Ambidexterity positively moderates the } \\
\text { relationship Manufacturing Flexibility and Firm Performance. }\end{array}$ \\
\hline Partanen et al. (2020) & $\begin{array}{l}200 \text { Sweden } \\
\text { Mfg. SMEs }\end{array}$ & $\begin{array}{l}\text { 1.Supply Chain Ambidexterity Negatively associated with } \\
\text { SME's Performance. } \\
\text { 2. Network Capabilities mitigates the negative relationship } \\
\text { between Supply Chain Ambidexterity and SME's Performance. } \\
\text { 3. Strategic Information Flow mitigates the negative relationship } \\
\text { between Supply Chain Ambidexterity and SME's Performance. }\end{array}$ \\
\hline $\begin{array}{l}\text { Rothaermel \& } \\
\text { Alexandre (2009) }\end{array}$ & $\begin{array}{l}141 \text { US } \\
\text { Mfg. Firms }\end{array}$ & $\begin{array}{c}\text { An inverted U-shaped relationship exists between a firm's total } \\
\text { Technology Sourcing Mix of (Known and New Technology) and } \\
\text { its performance. }\end{array}$ \\
\hline
\end{tabular}

\section{The mediating effect of organizational ambidexterity}

As in earlier discussion, inter-organizational learning is key for a firm to gain knowledge through EKS and mobilize it across each others' organizations for mutual benefit. While doing so, the firm needs to ensure that its core knowledge is well protected from potential leakage that may jeopardize the collaboration ties. Therefore, both EKS and KMobility compliment KP and reinforce each other to ensure that the relationship continues to grow. Some scholars claimed that ambidexterity in knowledge exchange and KP simultaneously will enable both organizations to gain performance of cooperation such as common benefit or private benefit (Yang et al., 2014). Likewise, another study also claimed that for a firm to increase its performance, pursuing both exploration and exploitation activities is key, and hence, it needs to foster inter-organizational knowledge exchange and intra-organizational learning concomitantly (Lin et al., 2013). In a similar vein, certain studies also confirmed that such collaborative ties between firms have a close link to knowledge acquisition and the firm ambidextrous innovation activities (Xie et al., 2019). Drawing from all these arguments, it is obvious that EKS, KMobility, and KP play a key role in facilitating the firm's ambidexterity activities. From this perspective, if a firm is able to transform all this new knowledge into radical or incremental innovative products or processes, then it is likely that the performance of the firm will improve (Lin et al., 2013). Vrontis et al. (2017) through their study also claimed that an ambidextrous knowledge-intensive firm will be able to constantly balance both its exploration and exploitation activities through the exploring of external knowledge sources and integrate it into existing knowledge stock for pursuing a greater firms' performance. For these reasons, if a firm is able to balance both its explorative and exploitative learning, it can fully capitalize on all its knowledge assets for optimum gain in its performance. Hence, the subsequent hypotheses are developed as follows:

H5. The relationship between EKS and MP is mediated by OA.

H6. The relationship between KMobility and MP is mediated by OA.

$H 7$. The relationship between KP and MP is mediated by OA. 


\section{CONCEPTUAL FRAMEWORK}

Through the discussion of literature and the hypotheses derived earlier, a conceptual framework of this study is conceived as shown in Figure 1. The interaction of the constructs and their relationship are grounded with RBV, KBV, $\mathrm{DC}$, and $\mathrm{OA}$ theories, which will be discussed in much detail in the subsequent section.

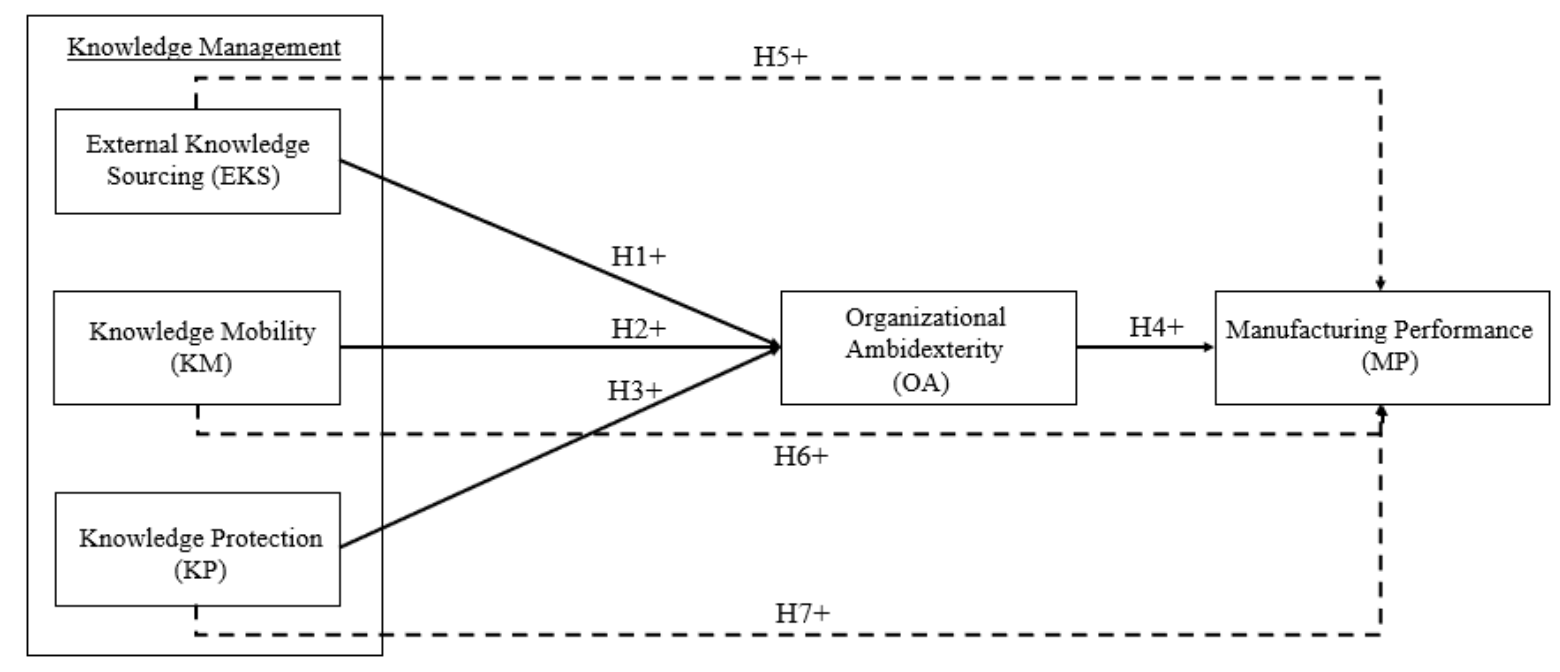

Figure 1. Conceptual framework

\section{UNDERLYING THEORY}

For this study, the theory of RBV, KBC, DC, and OA will substantiate the postulated hypotheses and the hypothesized conceptual framework. RBV stresses upon firm's resources that are valuable, rare, not able to emulate, and nonsubstitutable (Barney, 1991; Camisón \& Villar-López, 2014; Tang et al., 2019) as the main component of the firm to gain competitive advantage. However, such resources are not perpetually available as the market dynamic will render once a valuable resource is considered valueless for the firm (Barney, 1991). This notion reflects one of the problems that this study intends to resolve, which is the low labor cost that Malaysia used to have an edge over neighboring countries. However, with the emerging of IR4.0, technologies which enhance quality and productivity, and the key resource no longer has its competitive advantage (MITI, 2018).

However, such an operational predicament has been an on-going issue for manufacturers in different settings and market conditions. As a consequence, researchers started to consider the theory of DC which stresses the capabilities of the firm to sustain its competitiveness as the situation changes (Qamar et al., 2019; Sánchez et al., 2019; Teece et al., 1997). From the discussion of DC literature, a firm may not necessarily gain a competitive advantage by just having abundant resources if it does not possess the right set of abilities to react accordingly to the needs of a dynamic business environment (Teece et al., 1997). As an early proponent of the DC framework, Teece et al. (1997) pointed out the need for different research strategies from the field of innovation, manufacturing, organizational behavior, and business history to combine efforts into analyzing why firms perform differently at a certain environmental condition. This again reflects on the issues facing by the manufacturers, in which most only have low labor cost without the right skill sets and knowledge, thus leaving them in the lurch.

Drawing from such understanding, it is obvious that a firm will need to balance between sourcing and utilization of the key knowledge to the benefit of the organization. Therefore, the theory of OA demonstrates the importance of having ambidexterity within the firm for performance gain. Within OA literature, the concept usually being regarded as the ability of a firm to simultaneously pursues double and single-loop learning, incremental and radical innovation, induced and autonomous processes, or efficiency and flexibility in organization design (Raisch \& Birkinshaw, 2008). In this study, the focus will be on the aspect of explorative and exploitative learning activities within the firm. The firm that focuses on exploration might end up with many underdeveloped ideas and conversely firm that focuses on exploitation may miss out on new market opportunities or have products that are not meeting customers' preferences (March, 1991). Besides, both types of activities will contend for the same scarce resources within the firm, hence achieving a balance is vital for longrun sustainability. Considering the fact that many of the manufacturers have limited resources to adopt IR4.0, the results from the interaction between OA and KM will enable a manager to identify the correct level of learning approach to be taken at the right time according to the need of market dynamic (March, 1991). In reference to Malaysian manufacturers which are lacking slack resources to adopt IR4.0 technologies, elements of OA will provide an important linkage between $\mathrm{KM}$ and MP and also establish a theoretical justification for the proposed conceptual framework.

So far, all these three theories underscore the significance of acquiring the right knowledge and utilize it at the right time for the improvement of MP. However, there is a lack of information on how this knowledge can be properly managed 
for this purpose (Tan \& Wong, 2015). KBV theory from the seminal work of Grant (1996) provides complete theoretical reasoning by stressing the fact that the main priority of an organization is to properly utilize knowledge through transfer and protection that can lead to the development of the right decision for it to achieve sustainable competitive advantage. Grant (1996) also emphasized the need to protect one's knowledge resources so that firm can gain a longer competitive edge, and that is in alignment to RBV theory that stresses the importance of having rare and difficult to imitate resources for a firm to gain competitive advantage (Godfrey \& Hill, 1995). Likewise, the study of Leonard-barton (1992) on the core capabilities of the firm, claimed that a firm's success depends on its capacities to manage the evolution of its abilities in accordance with environmental dynamism. Building on this, the inclusion of OA into this study will provide further insight into how a firm can manage its knowledge with the exertion of external factors such as IR4.0 and achieve gains in MP.

In conclusion, in order to determine whether these theories reflect the actual outcome of the hypotheses, as Godfrey and Hill (1995, p. 530) stated "What scholars need to do is to theoretically identify what the observable consequences of unobservable resources are likely to be, and then go out see whether such predictions have a correspondence in the empirical world." Therefore, the positivist stand of this study will be confirmed by observable data set from the questionnaire survey. All the theoretical propositions put forward will be validated empirically, and the proposed conceptual framework will further extend the development of these theories.

\section{METHODOLOGY}

This study will be focusing on states with many manufacturing firms that have been identified as innovative by the National Survey of Innovation 2015 (MASTIC, 2015). Subsequently, the sample will be selected from the Federation of Malaysian Manufacturers (FMM) Directory 2018. Small-medium enterprises to large multinational corporations will be chosen for this study as this will provide a wider breadth of data collection needs. A structured questionnaire will be used due to the quantitative nature of this study. The questionnaire will be pretested by a panel of experts from both the industry and academia. Both e-mail and conventional mail will be chosen as the delivery method and will target operation managers, leaders, COO, or CEO. The questionnaire set consists of four main sections and a total of 33 items that measure KM, OA, and MP. A 6-point Likert Scale will be adopted for each of the items. A 12-items scale for MP will be adopted from Tamayo-Torres et al. (2017). As for measuring EKS, KMobility, KP, a total of 10 items will be adopted from Zhou and Li (2012) and Jean et al. (2014). As for OA, an 11-items scale will be adopted from Sahi et al. (2019). Finally, the measurement model will be assessed for constructs validity and reliability factor before the relationship of the structural model being analyzed using Smart-PLS.

\section{DISCUSSION AND CONCLUSION}

Malaysia's manufacturing sector facing challenges from neighboring countries with lower labor costs needs to regain its competitive edge through upskilling its workforce and improves its productivity through the application of IR4.0 technologies. However, various factors are compounding its progress and to understand what and how to mitigate them serves the basis of this study. Extant literature shows that proper management of the knowledge resources will lead to a better MP (Tan \& Wong, 2015) but does not satisfactorily inquire into the contingent factors that modulate the relationship between them. Factors such as EKS, KMobility, and KP are keys for improving MP and this study intends to fill the gaps in optimizing scarce resources to learn new external knowledge and strengthening the internal core knowledge for maximum gain in MP. Moreover, literature within the OA stream of research indicates that ambidextrous organizations have positive indicators related to MP. This has given rise to the objective of verifying the relationship between respective KM activities, OA, and MP and also to analyze the mediating effect of OA on KM and MP. This will be a seminal approach towards the understanding of MP enhancement using two streams of the research field. Besides having both practical and theoretical implications for managers and scholars, this study also provides a fresh perspective on the importance of protecting one's core knowledge resources towards balance learning and mobilizing new knowledge. Hypotheses grounded by RBV, KBV, DC, and OA are showing a positive impact of KM and OA on MP as well as the mediating role of $\mathrm{OA}$ within this relationship. A theoretical framework highlighting all the interconnections between the constructs is presented and also sets the avenue for further research for this unique interaction. 


\section{REFERENCES}

Abdallah, A. B., Phan, A. C., \& Matsui, Y. (2016). Investigating the effects of managerial and technological innovations on operational performance and customer satisfaction of manufacturing companies. International Journal of Business Innovation and Research, 10(2-3), 153-183. https://doi.org/10.1504/IJBIR.2016.074824

Aboelmaged, M. G. (2014). Linking operations performance to knowledge management capability: The mediating role of innovation performance. Production Planning and Control, 25(1), 44-58. https://doi.org/10.1080/09537287.2012.655802

Al-Sa'di, A. F., Abdallah, A. B., \& Dahiyat, S. E. (2017). The mediating role of product and process innovations on the relationship between knowledge management and operational performance in manufacturing companies in Jordan. Business Process Management Journal, 23(2), 349-376. https://doi.org/10.1108/BPMJ-03-2016-0047

Antunes, M. G., Quirós, J. T., \& Justino, M. do R. F. (2017). The relationship between innovation and total quality management and the innovation effects on organizational performance. International Journal of Quality and Reliability Management, 34(9), 1474-1492. https://doi.org/10.1108/IJQRM-02-2016-0025

Barney, J. (1991). Firm Reources ad Sustained Competitive Advantege. In Journal of Management (Vol. 17, Issue 1, pp. 99-120). https://doi.org/10.1177/014920639101700108

Brunswicker, S., \& Vanhaverbeke, W. (2015). Open Innovation in Small and Medium-Sized Enterprises (SMEs): External Knowledge Sourcing Strategies and Internal Organizational Facilitators. Journal of Small Business Management, 53(4), $1241-1263$. https://doi.org/10.1111/jsbm.12120

Camisón, C., \& Villar-López, A. (2014). Organizational innovation as an enabler of technological innovation capabilities and firm performance. Journal of Business Research, 67(1), 2891-2902. https://doi.org/10.1016/j.jbusres.2012.06.004

Dezi, L., Ferraris, A., Papa, A., \& Vrontis, D. (2019). The Role of External Embeddedness and Knowledge Management as Antecedents of Ambidexterity and Performances in Italian SMEs. IEEE Transactions on Engineering Management, 1-10. https://doi.org/10.1109/tem.2019.2916378

Doran, J., \& Mccarthy, N. (2019). THE IMPORTANCE OF INTERNAL KNOWLEDGE GENERATION AND EXTERNAL KNOWLEDGE SOURCING FOR SME INNOVATION AND PERFORMANCE: EVIDENCE FROM IRELAND. International Journal of Innovation Management, 1950069, 1-30. https://doi.org/10.1142/S1363919619500695

Estrada, I., Faems, D., \& de Faria, P. (2016). Coopetition and product innovation performance: The role of internal knowledge sharing mechanisms and formal knowledge protection mechanisms. Industrial Marketing Management, 53, 56-65. https://doi.org/10.1016/j.indmarman.2015.11.013

Godfrey, P. C., \& Hill, C. W. L. (1995). The problem of unobservables in strategic management research. Strategic Management Journal, 16(7), 519-533. https://doi.org/10.1002/smj.4250160703

Grant, R. M. (1996). Toward a knowledge-based theory of the firm. Strategic Management Journal, 17(Special Issue), 109-122. https://doi.org/10.1002/smj.4250171110

Hagedoorn, J., \& Cloodt, M. (2003). Measuring innovative performance: Is there an advantage in using multiple indicators? Research Policy, 32(8), 1365-1379. https://doi.org/10.1016/S0048-7333(02)00137-3

Han, Y. (2019). THE RELATIONSHIP BETWEEN AMBIDEXTROUS KNOWLEDGE SHARING AND INNOVATION WITHIN INDUSTRIAL CLUSTERS: EVIDENCE FROM CHINA. Interdisciplinary Journal of Information, Knowledge, and Management, 14, 145-163. https://doi.org/https://doi.org/10.28945/4299 (CC

He, Z. L., \& Wong, P. K. (2004). Exploration vs. exploitation: An empirical test of the ambidexterity hypothesis. Organization Science, 15(4), 481-495. https://doi.org/10.1287/orsc.1040.0078

Jean, R. J. B., Sinkovics, R. R., \& Hiebaum, T. P. (2014). The effects of supplier involvement and knowledge protection on product innovation in customer-supplier relationships: A study of global automotive suppliers in China. Journal of Product Innovation Management, 31(1), 98-113. https://doi.org/10.1111/jpim.12082

Kim, C. Y., Lim, M. S., \& Yoo, J. W. (2019). Ambidexterity in external knowledge search strategies and innovation performance: Mediating role of balanced innovation and moderating role of absorptive capacity. Sustainability (Switzerland), 11(18). https://doi.org/10.3390/su11185111

Leonard-barton, D. (1992). Core Capabilities and Core Rigidties: A Paradox In Managing New Product Development. Strategic Management Journal, 13, 111-125. https://doi.org/10.1002/smj.4250131009

Liao, S. H., \& Wu, C. chuan. (2010). System perspective of knowledge management, organizational learning, and organizational innovation. Expert Systems with Applications, 37(2), 1096-1103. https://doi.org/10.1016/j.eswa.2009.06.109

Liebeskind, J. P. (1996). Knowledge, strategy, and the theory of the firm. Journal of Strategic Management, 17(Winter Special Issue), 93-107. https://doi.org/10.1016/b978-0-7506-7088-3.50014-0

Lin, H. E., McDonough, E. F., Lin, S. J., \& Lin, C. Y. Y. (2013). Managing the exploitation/exploration paradox: The role of a learning capability and innovation ambidexterity. Journal of Product Innovation Management, 30(2), $262-278$. https://doi.org/10.1111/j.1540-5885.2012.00998.x

Liu, C. L. (Eunice). (2012). Knowledge Mobility in Cross-Border Buyer-Supplier Relationships. Management International Review, 52(2), 275-291. https://doi.org/10.1007/s11575-012-0138-z

March, J. G. (1991). Exploration and Exploitation in Organizational Learning. Organization Science, 2(1), $71-87$. https://doi.org/10.1287/orsc.2.1.71

MASTIC, (2015). National Survey of Innovation. https://mastic.mestecc.gov.my/sti-survey-content-spds/national-\%0Asurveyinnovation-2015\%0A

MITI, (2018). Industry 4wrd: National Policy on Industry 4.0. https://www.miti.gov.my/miti/resources/National Policy on Industry 4.0/Industry4WRD_Final.pdf

OECD, (2005). Oslo manual: Proposed Guidelines for Collecting and Interpreting Technological Innovation Data. Paris

Olander, H., Vanhala, M., \& Hurmelinna-Laukkanen, P. (2014). Reasons for choosing mechanisms to protect knowledge and innovations. Management Decision, 52(2), 207-229. https://doi.org/10.1108/MD-11-2012-0791

Oorschot et al., K. E. V. et al. (2018). The knowledge protection paradox : imitation and innovation through knowledge sharing. Int. J. Technology Management, 78(4), 310-342. https://doi.org/10.1504/ijtm.2018.095760

Partanen, J., Kohtamäki, M., Patel, P. C., \& Parida, V. (2020). Supply chain ambidexterity and manufacturing SME performance: The moderating roles of network capability and strategic information flow. International Journal of Production Economics, 
221(August), 107470. https://doi.org/10.1016/j.ijpe.2019.08.005

Patel, P. C., Terjesen, S., \& Li, D. (2012). Enhancing effects of manufacturing flexibility through operational absorptive capacity and operational ambidexterity. Journal of Operations Management, 30(3), 201-220. https://doi.org/10.1016/j.jom.2011.10.004

Qamar, A., Hall, M. A., Chicksand, D., \& Collinson, S. (2019). Quality and flexibility performance trade-offs between lean and agile manufacturing firms in the automotive industry. Production Planning and Control, O(0), 1-16. https://doi.org/10.1080/09537287.2019.1681534

Raisch, S., \& Birkinshaw, J. (2008). Organizational ambidexterity: Antecedents, outcomes, and moderators. Journal of Management, 34(3), 375-409. https://doi.org/10.1177/0149206308316058

Rothaermel, F. T., \& Alexandre, M. T. (2009). Ambidexterity in technology sourcing: The moderating role of absorptive capacity. Organization Science, 20(4), 759-780. https://doi.org/10.1287/orsc.1080.0404

Ruiz-Jiménez, J. M., \& Fuentes-Fuentes, M. D. M. (2013). Knowledge combination, innovation, organizational performance in technology firms. Industrial Management and Data Systems, 113(4), 523-540. https://doi.org/10.1108/02635571311322775

Sahi, G. K., Gupta, M. C., \& Cheng, T. C. E. (2019). The effects of strategic orientation on operational ambidexterity: A study of indian SMEs in the industry 4.0 era. International Journal of Production Economics, 220(August 2018), 107395. https://doi.org/10.1016/j.ijpe.2019.05.014

Sánchez, Á. M., Pérez-Pérez, M., \& Vicente-Oliva, S. (2019). Agile production, innovation and technological cooperation: Overlapping priorities of manufacturing firms. Baltic Journal of Management, 14(4), 597-615. https://doi.org/10.1108/BJM-12-2018-0410

Tamayo-Torres, J., Roehrich, K., J., \& A. Lewis, M. (2017). Ambidexterity, performance and environmental dynamism. International Journal of Operations \& Production Management, Vol. 37(3), 282-299. https://doi.org/https://doi.org/10.1108/IJOPM-062015-0378

Tan, L. P., \& Wong, K. Y. (2015). Linkage between knowledge management and manufacturing performance: a structural equation modeling approach. Journal of Knowledge Management, 19(4), 814-835. https://doi.org/10.1108/JKM-11-2014-0487

Tang, M., Xu, P., Llerena, P., \& Jahanshahi, A. A. (2019). The impact of the openness of firms' external search strategies on exploratory innovation and exploitative innovation. Sustainability (Switzerland), 11(18). https://doi.org/10.3390/su11184858

Teece, D. J., Pisano, G., \& Shuen, A. (1997). Dynamic capabilities and strategic management: organizing for innovation and growth. Strategic Management Journal, 18(7), 509-533. https://doi.org/https://doi.org/10.1002/(SICI)10970266(199708)18:7<509::AID-SMJ882>3.0.CO;2-Z

Vázquez-Bustelo, D., Avella, L., \& Fernández, E. (2007). Agility drivers, enablers and outcomes: Empirical test of an integrated agile manufacturing model. International Journal of Operations and Production Management, 27(12), $1303-1332$. https://doi.org/10.1108/01443570710835633

Vrontis, D., Thrassou, A., Santoro, G., \& Papa, A. (2017). Ambidexterity, external knowledge and performance in knowledge-intensive firms. Journal of Technology Transfer, 42(2), 374-388. https://doi.org/10.1007/s10961-016-9502-7

Xie, X., Gao, Y., Zang, Z., \& Meng, X. (2019). Collaborative ties and ambidextrous innovation: insights from internal and external knowledge acquisition. Industry and Innovation, 27(3), 285-310. https://doi.org/10.1080/13662716.2019.1633909

Yang, S. M., Fang, S. C., Fang, S. R., \& Chou, C. H. (2014). Knowledge exchange and knowledge protection in interorganizational learning: The ambidexterity perspective. Industrial Marketing Management, 43(2), 346-358. https://doi.org/10.1016/j.indmarman.2013.11.007

Zhou, K. Z., \& Li, C. B. (2012). How Knowledge Affects Radical Innovation: Knowledge Base, Market Knowledge Acquisition, and Internal Knowledge Sharing. Strategic Management Journal, 33(May 2009), 1090-1102. https://doi.org/10.1002/smj

\section{ACKNOWLEDGEMENT}

The researchers would like to thank DR. Suzari Abdul Rahim from the Graduate School of Business in Universiti Sains Malaysia, Malaysia, for his invaluable comments and guidance in this study. 


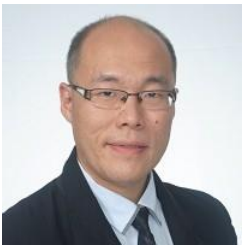

Cheah Seng Cheong is a Ph.D. scholar attaches to the Graduate School of Business in Universiti Sains Malaysia. He holds a BSEE degree from Iowa State University, USA, and an MBA degree from Universiti Sains Malaysia. He has 18 years of Manufacturing experience. His research focus is on innovation and operations management.

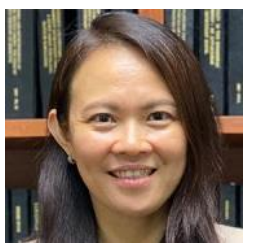

Dr. Tan Cheng Ling is currently an Associate Professor at the Graduate School of Business at the Universiti Sains Malaysia. 